\title{
Blends of surfactants and EVA as cold flow improvers for diesel fuels
}

\author{
W. Zheng' ${ }^{2}$, S. Wang ${ }^{1,2}$, F. Meng ${ }^{1,2} \&$ W. Lv ${ }^{1}$ \\ ${ }^{1}$ State Key Laboratory of Heavy Oil Processing, \\ China University of Petroleum, China \\ ${ }^{2}$ College of Science, China University of Petroleum, China
}

\begin{abstract}
The content and carbon number distribution of n-alkanes in diesel samples was analyzed using gas chromatography (GC). This paper describes one kind of commercial ethylene/vinyl acetate (EVA) additive for evaluating the sensitivity of four diesel samples. The influence of surfactants added alone or compounded with EVA on the cold flow plugging point (CFPP) was determined to investigate the collaborative effect. The results indicated that the susceptibility of diesel samples was according to the following order: $2^{\#}, 3^{\#}, 1^{\#}$ and $4^{\#}$, and the synergistic effect of surfactants combined with EVA was excellent. To further the development of surfactants as cold flow improvers, the performance mechanism was studied using differential scanning calorimetry (DSC). The results show that the crystallization energy of wax crystals had different degrees of decline with the use of the additive surfactants, through measuring the thermal effects using DSC.

Keywords: surfactant, diesel, cold flow plugging point, crystallization process, mechanism.
\end{abstract}

\section{Introduction}

A cold flow improver (CFI) is a kind of additive that can effectively improve the flow property of diesel at low temperatures [1]. Owing to the wide variety of oil components, many polymers were developed as pour point depressants (PPD) to affect the flow property of diesel via adjusting the precipitation [2, 3]. In general, these polymers have a wax-like paraffin part, which provides the interaction between the additive and paraffin, and a polar segment that is responsible for 
modifying the morphology of wax crystals $[4,5]$. The most extensively used flow improver for diesel is ethylene-vinyl acetate copolymer [6].

However, because of the difference between the structures of diesel oils is very large, PPD for one kind of diesel may not be suitable for another kind of diesel. So it is necessary to blend PPD with other compounds (e.g. surfactants) to expand the scope of their performance. In recent years, small molecular surfactants have been more and more recognized for their collaborative effect, particularly the effect of suppressing separated wax [7].

The content and carbon number distribution of n-alkanes in four diesels obtained from different processing technologies were characterized by gas chromatography (GC). The effect of commercial EVA, surfactants and their blends on the cold flow plugging point (CFPP) of diesel oil was evaluated.

\section{Experimental section}

\subsection{Materials}

In the experiment, $1^{\#}$ and $2^{\#}$ fluid catalytic cracking (FCC) diesel samples were derived from Daqing Petrochemical Corporation, China and Shijiazhuang Petrochemical Corporation, China, respectively; 3\# hydrogenation diesel and 4\# straight-run diesel were obtained from Yanhua Petrochemical Corporation, China.

The following surface-active agents were purchased from Tianjin Guangfu Fine Chemical Research Institute, China: Span 80, Span 65, Span 60, Span 40, Tween 80 , Tween 60 and Tween 20. The substances were graded chemically pure and employed without further purification. EVA was supplied by Yixing Kingone Chemical Technology Co. Ltd., China.

\subsection{Cold filter plugging point measurement}

According to SH/T0248-92 standard methods, the CFPP of diesel fuels was determined by the SWXK-402D multifunctional tester for a petroleum product made by Shanghai Pengpu Refrigeration Corporation, China. CFPP is the highest temperature at which a given volume of diesel cannot pass a 363 mesh filter under 1961 Pa pressure within 60s.

\section{3 n-alkane determination in diesel fuels}

The content of n-paraffins and carbon numbers in $1^{\#}, 2^{\#}, 3^{\#}$ and $4^{\#}$ diesel samples were determined by a gas chromatograph (HP-PONA) with an AN-5 capillary column $(50 \mathrm{~mm} \times 0.2 \mathrm{~mm} \times 0.5 \mu \mathrm{m})$.

The GC operating conditions were as follows: the temperature of the capillary column was progressively raised by $4.5^{\circ} \mathrm{C} / \mathrm{min}$ from $35^{\circ} \mathrm{C}$ to $300^{\circ} \mathrm{C}$, the injector temperature was $300^{\circ} \mathrm{C}$, the FID detector temperature was $300^{\circ} \mathrm{C}$, the injection volume was $1 \mu \mathrm{m}$, the carrier gas $\mathrm{N}_{2}$ was $20 \mathrm{ml} / \mathrm{min}, \mathrm{H}_{2}$ was $30 \mathrm{ml} / \mathrm{min}$, and the distribution ratio was 50:1. 


\subsection{Thermal analysis by Differential Scanning Calorimeter (DSC)}

The cooling curves of the $2^{\#}$ diesel sample, both untreated and treated with CFI, were obtained using a Differential Scanning Calorimeter 204 F1 (Netzsch Co., Germany). Samples of 5-10mg were sealed in hermetic aluminium pans at $20^{\circ} \mathrm{C}$, and immediately cooled down to $-30^{\circ} \mathrm{C}$, with a cooling rate of $2^{\circ} \mathrm{C}$.

\section{Results and discussion}

\subsection{Concentration distribution of n-paraffin composition of diesel oil samples}

It is known that the susceptibility of diesel fuels to CFI is related to its chemical composition and processing technique [8]. From a composition point of view, the susceptibility is good when the diesel fuel contains a wide carbon number distribution, a high content of aromatic hydrocarbons and a low content of n-alkanes. In terms of processing technique, the order of susceptibility of diesel fuels to CFI is: catalytic cracking (FCC) diesel > hydrogenation diesel > straightrun diesel. The carbon number distribution of n-paraffin was examined by a gas chromatograph, as shown in Figure 1.

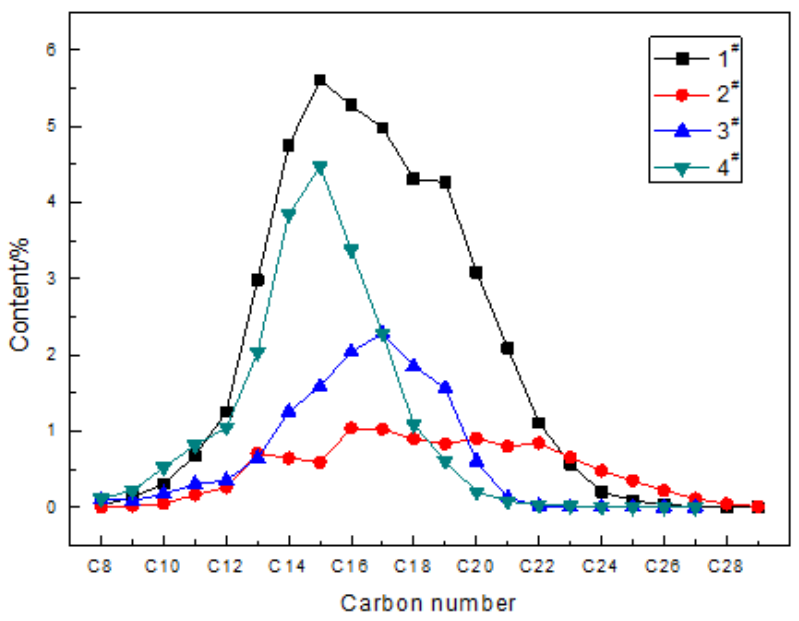

Figure 1: The carbon number distribution of diesel oil samples.

It can be seen that the paraffin of sample $1^{\#}$ is wide and ranges from $\mathrm{C}_{8}$ to $\mathrm{C}_{29}$. The crest value in fuel $2^{\#}$ is $\mathrm{C}_{16}$, and the n-alkanes carbon distribution is wide and ranges from $C_{8}$ to $C_{29}-$ mainly from $C_{13}$ to $C_{22}$. The wax distribution in sample $3^{\#}$ mainly ranges from $\mathrm{C}_{15}$ to $\mathrm{C}_{19}$. The high-alkanes carbon distribution in diesel $4^{\#}$ is narrow, ranging from $\mathrm{C}_{14}$ to $\mathrm{C}_{17}$. It can be noted from Figure 1 that the content of n-alkanes of diesel samples decreases according to the following 
order: $1^{\#}, 4^{\#}, 3^{\#}$ and $2^{\#}$. From a processing technique point of view, we know that the susceptibility of diesel fuels to CFI would be $1^{\#}, 2^{\#}>3^{\#}>4^{\#}$. It can be foreseen that $3^{\#}$ and $4^{\#}$ diesel samples show a low sensitivity to CFI, and $2^{\#}$ will show a better sensitivity than other diesel samples.

\subsection{The effect of EVA on cold flow plugging point depression ( $\triangle$ CFPP) of the tested fuels}

The cold flow performance of diesel oil samples was evaluated by the commercial EVA with different dosages. The results are described in Table 1.

Table 1: The effect of EVA on $\triangle \mathrm{CFPP}$ of the tested fuels.

\begin{tabular}{cccccccc}
\hline \multirow{2}{*}{ Samples } & \multicolumn{7}{c}{$\Delta$ CFPP $\left({ }^{\circ} \mathrm{C}\right)$} \\
\cline { 2 - 8 } & $0 \%$ & $0.03 \%$ & $0.05 \%$ & $0.08 \%$ & $0.1 \%$ & $0.15 \%$ & $0.2 \%$ \\
\hline $1^{\#}$ & 0 & 1 & 2 & 3 & 3 & 3 & 3 \\
$2^{\#}$ & 0 & 4 & 5 & 5 & 5 & 5 & 5 \\
$3^{\#}$ & 0 & 2 & 3 & 4 & 4 & 4 & 4 \\
$4^{\#}$ & 0 & 0 & 0 & 1 & 1 & 1 & 1 \\
\hline
\end{tabular}

It can be seen that the CFPP of $1^{\#}, 2^{\#}, 3^{\#}$ and $4^{\#}$ diesel samples were lowered by $3^{\circ} \mathrm{C}, 5^{\circ} \mathrm{C}, 4^{\circ} \mathrm{C}$ and $1^{\circ} \mathrm{C}$, respectively. Combined with Figure 1 , the $\triangle \mathrm{CFPP}$ should decrease according to the following order: $2^{\#}>3^{\#}>4^{\#}>1^{\#}$ or $1^{\#}, 2^{\#}>3^{\#}>$ $4^{\#}$ from different viewpoints. However, based on the information contained in Table 2, we know that the sensitivity of diesel samples is according to the following order: $2^{\#}, 3^{\#}, 1^{\#}$ and $4^{\#}$. The results of $2^{\#}$ and $3^{\#}$ are in accordance with the previous conclusion, while $1^{\#}$ and $4^{\#}$ are not. It can be concluded that both the chemical composition and the processing technique affect the susceptibility of diesel fuels to CFI, and the processing technique would be the dominant factor.

\subsection{The effect of surfactant on $\triangle \mathrm{CFPP}$ of diesel samples}

The cold flow performance of the surfactant was evaluated for diesel samples $1^{\# \text {, }}$ $2^{\#}$ and $3^{\#}$ at an additive concentration of $500 \mathrm{ppm}$. The results are listed in Table 2.

Table 2: Effect of dosage of surfactant on $\triangle \mathrm{CFPP}$ of diesel samples.

\begin{tabular}{cccccccc}
\hline \multirow{2}{*}{ Samples } & \multicolumn{7}{c}{$\Delta$ CFPP $\left({ }^{\circ} \mathrm{C}\right)$} \\
\cline { 2 - 8 } & Span40 & Span 60 & Span65 & Span80 & Tween20 & Tween60 & Tween80 \\
\hline $1^{\#}$ & 1 & 0 & 0 & 0 & Insoluble & Insoluble & Insoluble \\
$2^{\#}$ & 1 & 1 & 0 & 0 & Insoluble & Insoluble & Insoluble \\
$3^{\#}$ & 1 & 0 & 1 & 0 & Insoluble & Insoluble & Insoluble \\
\hline
\end{tabular}

The results show that the effect of surfactant on $\triangle \mathrm{CFPP}$ of diesel samples was poor, and the Tween surfactant was insoluble in diesel. It is known that the main ingredient of the Tween surfactant is polyoxyethylene sorbitan fatty acid ester, and 
the solubility in oil is strongly linked with the length of the polyoxyethylene chain segment. The polyoxyethylene chain segment contains 20 ethoxy groups in Tween 20, 60 and 80, and what's more, the hydrophile-lipophile balance (HLB) value is between 14.9 and 16.7. As a result, the solubility of Tween surfactants was very poor.

\subsection{The effect of EVA mixed with surfactants on $\triangle$ CFPP of diesel samples}

According to Zhao et al. [9] and Wang et al. [10], surface active agents have good solubilization properties: a) the surfactants molecules, especially the hydrophobic part, have an affinity with the pour point depressant; b) the pour point depressant can enter the in-layer of micelles. Due to the dual reasons, the surface free energy of the system was reduced and the solubility of PPD was increased. To investigate the synergistic effect of surfactants combined with EVA, the cold flow performance of the compound was evaluated for $2^{\#}$ diesel sample with a dosage of 500 ppm. The results are described in Table 3.

Table 3: The CFPP depression effect from the mixing ratio of spans and EVA.

\begin{tabular}{ccccc}
\hline \multirow{2}{*}{ proportion } & \multicolumn{4}{c}{$\Delta$ CFPP $\left({ }^{\circ} \mathrm{C}\right)$} \\
\cline { 2 - 5 } & Span40 & Span 60 & Span 65 & Span 80 \\
\hline $4: 1$ & 7 & 8 & 8 & 7 \\
$1: 1$ & 4 & 5 & 6 & 5 \\
$1: 4$ & 3 & 4 & 3 & 4 \\
\hline
\end{tabular}

From Table 3, it is observed that there is almost no synergistic effect when EVA was used as an accessory ingredient. However, the coagulation depressing effect was great when EVA and Spans were combined at a ratio of 4:1.

Combined with the data in Table 1, the effect of Span-EVA compounds on $\triangle \mathrm{CFPP}$ of the $2^{\#}$ sample was better than EVA being singly applied, the CFPP can be reduced by $3^{\circ} \mathrm{C}$ in the basis of using EVA alone. We can draw the conclusion that the synergistic effect was excellent. There are two reasons that explain the phenomenon: (a) sorbitan stearate (Span 60), sorbitan tristearate (Span 65) and Sorbitan oleate (Span 80) were all molecules with 18-alkyl chain lengths, which correspond to the content of the n-alkane in diesel sample $2^{\#}$; (b) the polarity of ester group in surfactants increased the dispersity of CFI and wax, and changed the crystallizing habits. Thus, the surfactants exhibited a good collaborative effect when compounded with EVA.

\subsection{The effect of mixed Spans matched with EVA on $\triangle$ CFPP of diesel samples}

In order to evaluate the effect of mixed Spans compounded with EVA on $\triangle \mathrm{CFPP}$ of diesel sample $2^{\#}$, Span 40 , Span 60 and Span 80 were blended at ratios of 1:2:2, 1:1:2, 1:2:1, 2:1:1, 2:1:2, and marked as A1-A5, respectively. Then the accessory ingredients were mixed with EVA at a ratio of 1:4. Table 4 shows the results, where the total additive concentration was $500 \mu \mathrm{g} / \mathrm{g}$. 
Table 4: Decrease CFPP Effect of Mixed Spans Matched with EVA.

\begin{tabular}{cccccc}
\hline & \multicolumn{5}{c}{ Composition of CFI } \\
\cline { 2 - 6 } & EVA-A $_{1}$ & EVA-A $_{2}$ & EVA-A $_{3}$ & EVA-A $_{4}$ & EVA-A $_{5}$ \\
\hline$\Delta$ CFPP $\left({ }^{\circ} \mathrm{C}\right)$ & 8 & 9 & 10 & 8 & 8 \\
\hline
\end{tabular}

The CFPP of the sample $2^{\#}$ with span $\mathrm{A}_{3}$ and EVA were lowered by $10^{\circ} \mathrm{C}$, which was two times that of using EVA alone. According to the previous empirical analysis and pertinent literature by Hu et al. [11], the probable mechanism is that surfactants are compounds of small molecules, which contain two parts: a longchain alkane and a polar group. The surfactants can poison the crystallization due to the polar groups and eutectic with wax, relying on long-chain alkanes, which hinder the wax crystal molecules from aggregation at the molecular level. So the wider the long-chain alkane of surfactants ranged, the better the eutectic was affected, and the better the performance was.

\subsection{Analysis of sub-ambient DSC data}

Differential scanning calorimetry (DSC) is one of the useful techniques in evaluating the effect of temperature on properties of materials, which has the following advantages: high measurement speed, small quantity of sample, diversified sample state (liquid and solid) and simple date analysis [12]. This method has been widely used to study the process of wax precipitation since it could determine the temperature of wax precipitation phase transition and the thermal properties [13].

The DSC cooling curves based on downward temperature sweep test were performed for diesel sample $2^{\#}$ with and without CFI (Figure 2). Table 5 summarizes the relevant wax appearance temperature (WAT), peak temperature, and $\Delta H_{\text {cryst }}$ (enthalpy of crystallization) resulting from the analysis of these curves.

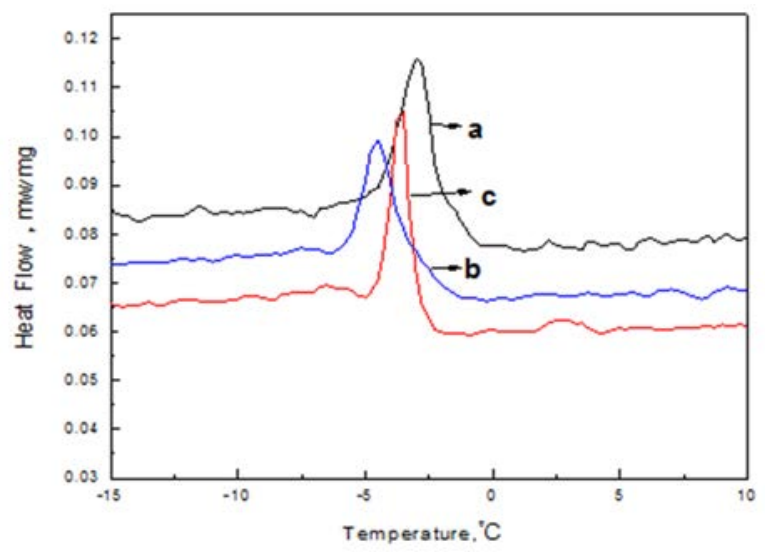

Figure 2: The DSC curves for diesel sample $2^{\#}$. a: blank diesel sample $2^{\# \text {; }}$ b: sample $2^{\#}$ diesel with EVA; c: sample $2^{\#}$ diesel with EVA-A3 (see Table 4, ratio of 4:1). 
Table 5: The results of DSC curves for diesel sample 2\#.

\begin{tabular}{ccccc}
\hline Samples & CFPP $\left({ }^{\circ} \mathrm{C}\right)$ & WAT $\left({ }^{\circ} \mathrm{C}\right)$ & Peak T $\left({ }^{\circ} \mathrm{C}\right)$ & $\Delta H_{\text {cryst }}\left(\mathrm{J} \cdot \mathrm{g}^{-1}\right)$ \\
\hline a & 5 & -0.4 & -3.0 & 1.617 \\
b & 0 & -1.0 & -4.5 & 1.306 \\
c & -5 & -2.5 & -3.5 & 1.169 \\
\hline
\end{tabular}

$\Delta H_{\text {cryst }}$ represents the enthalpy of crystallization found using DSC.

As it can be seen in Figure 2 and Table 5, the enthalpy of crystallization decreased according to the following order: blank diesel sample $2^{\#}$, diesel sample $2^{\#}$ disposed with EVA and sample $2^{\#}$ diesel treated with EVA-A3 (as shown in Table 4, ratio of 4:1) which can be simplified as a $>b>c$. The temperature of wax appearance decreased according to the following order: a, b and c, which were in accordance with the order of CFPP. However, the WAT is far different from the CFPP, which may be caused by the difference in cooling rates [14]. It is observed from curves $a$ and $b$ that the slope of curve $a$ is greater than curve $b$, and it can be inferred that the wax precipitated gently after adding EVA in the diesel. However, it should be noted that the rake ratio of curve c is sharper than that of curve b. A possible reason for this is that the surfactants dissolved out earlier than the wax crystal and then other crystals grew around the nucleus to promote the growth of the wax crystal.

According to the analysis above, we came to the conclusion that the effect of EVA on CFPP of diesel mainly occurred because of a eutectic reaction. The nonpolar part of EVA co-crystallized with wax molecules at the wax appearance temperature, while the polar part hindered the crystals' further growth [15]. On the contrary, the surfactants may act as a nucleus of the wax growth, and the wax crystals separated quickly from diesel, then the formation of a wax crystal threedimensional (3D) network structure would be prevented by the eutectic effect of EVA on wax. The surface active agent as small molecules cannot directly modify the surface properties of wax crystal. The cooperative effect between PPD and surface active agent will induce PPD to easily attract on the surface of wax.

\section{Conclusions}

The susceptibility of EVA on $\triangle$ CFPP of diesels is not only closely related to the content of the diesel fuels, but also relevant to the processing technologies of diesel samples. EVA alone can maximally depress the CFPP of $1^{\#}, 2^{\#}, 3^{\#}$ and $4^{\#}$ samples by $3^{\circ} \mathrm{C}, 5^{\circ} \mathrm{C}, 4^{\circ} \mathrm{C}$ and $1^{\circ} \mathrm{C}$, respectively; however, the surfactants have almost no effect on dropping CFPP. The surfactants exhibit a good collaborative effect when compounded with EVA. The CFPP of the sample $2^{\#}$ was reduced by $10^{\circ} \mathrm{C}$ when the mixed Span $\mathrm{A}_{3}$ was used together with EVA.

According to the analysis of enthalpy of crystallization, we can draw the following conclusions: the enthalpy of crystallization was further decreased by surfactants, while the surface properties of wax crystal could not be changed by surfactants. The most likely behaviour of the surfactant on dropping CFPP of 
diesel would be as follows: the surfactants act as a nucleus of the wax growth with the decreasing temperature, and the EVA would rapidly co-crystallize with wax molecules. Due to the strong polarity of the $\mathrm{COOCH}_{3}$ group of EVA, the morphology of wax changes from original lamellar sheets to small needle crystals to prevent the formation of a 3D network structure.

\section{Acknowledgement}

The authors thank the financial support of the Basic Research Program of the State Key Laboratory of Heavy Oil Processing, China University of Petroleum, Beijing, PR China.

\section{References}

[1] Zhang H. K., Liu H. Y. and Wang S. J. A new alternating copolymerized derivatives as a cold flow improver for diesel fuel. Petroleum Science, 6, pp. 82-85, 2009.

[2] Zhang J. L., Zhang M., Wan J. J., Li W. Theoretical study of the prohibited mechanism for ethylene/ vinyl acetate co-polymers to the wax crystal growth. Journal of Physical Chemistry B, 112, pp. 36-43, 2008.

[3] Pedersen K. S., Ronningsen H. P. Influence of wax inhibitors on wax appearance temperature, pour point, and viscosity of waxy crude oils. Energy \& Fuels, 17, pp. 321-328, 2003.

[4] Feng L. J., Zhang Z. Q., Wang F., et al. Synthesis and evaluation of alkyl acrylate-vinyl acetate-maleic anhydride terpolymers as cold flow improvers for diesel fuel. Fuel Processing Technology, 118, pp. 42-48, 2014.

[5] Kuzmic A. E., Radosevic M., Bogdanic G., et al. Studies on the influence of long chain acrylic esters polymers with polar monomers as crude oil flow improver additives. Fuel, 87, pp. 2943-50, 2008.

[6] Deshmukh S, Bharambe D. P. Synthesis of polymeric pour point depressants for Nada crude oil (Gujarat, India) and its impact on oil rheology. Fuel Processing Technology; 89, pp. 227-233, 2008.

[7] Zheng W. G., Wang S. J, Liu J., et al. Synthesis and evaluation of wax dispersant for diesel. Energy and Fuels, 28, pp. 1896-1900, 2014.

[8] Du T, Wang S. J., Liu H. Y., Liu J. Study on commercial pour point depressants lowering cold filter plugging point for Daqing diesel fuels. Petroleum Science and Technology, 31, pp.1078-1084, 2013.

[9] Zhao R. X., Li D. D., Yao K. X., et al. The study on the compound use of the diesel low temperature flowing improvement agent. Tianjin Chemical Industry, 18, pp. 34-36, 2004.

[10] Wang B., Zhang H. B., Zhang F. S., et al. A study on a new tape pour point depressant used for crudes. Acta Petrolei Sinica, 19, pp. 97-103, 1998.

[11] Hu TP, Xu GP, Zhang YM. Preparation of novel wax crystal dispersant for diesel fuel and its application in decreasing pour point. Advances in Fine Petrochemicals. 10, pp. 16-19, 2009. 
[12] Senra M., Scholand T., Maxey C., Fogler H. S. Role of polydispersity and cocrystallization on the gelation of long-chained n-alkanes in solution. Energy and Fuels, 23, pp. 5947-5957, 2009.

[13] Sharma B. K., Doll K. M., Erhan S. Z. Ester hydroxyl derivatives of methyl oleate: tribological, oxidation and low temperature properties. Bioresource Technology, 99, pp. 7333-7340, 2008.

[14] Quinchia L. A., Delgado M. A., Franco J. M., Spikes H. A., Gallegos C. Low-temperature flow behavior of vegetable oil-based lubricants. Industrial Crops and Products, 37, pp. 383-388, 2012.

[15] Li H. P., Li H. J., Shen B. X. Advances in research of cold flow properties of diesel fuel. Modern Chemical Industry, 26, pp. 24-29, 2006. 